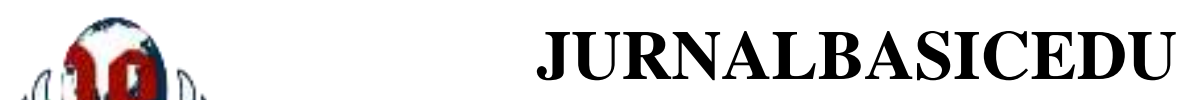

Volume 5 Nomor 5 Tahun 2021 Halaman 3841 - 3849

Research \&Learningin Elementary Education https://jbasic.org/index.php/basicedu

P. ALLASTAS

\title{
Pengaruh Penerapan Model Pembelajaran Mind Mapping terhadap Hasil Belajar IPA Siswa Sekolah Dasar di Masa Pandemi Covid-19
}

\author{
Inisti Adelia Ruhama ${ }^{1 凶}$, Erwin $^{2}$ \\ Pendidikan Guru Sekolah Dasar, Universitas Muhammadiyah Prof. Dr. HAMKA ${ }^{1,2}$ \\ E-mail: inistifattah99@gmail.com ${ }^{1}$, erwin@uhamka.ac.id ${ }^{2}$
}

\begin{abstract}
Abstrak
Latar belakang dari penelitian ini adalah rendahnya hasil belajar IPA dilihat dari KKM yaitu 68 dimana $43,75 \%$ siswa kelas IV memiliki nilai dibawah KKM. Penelitian ini dilakukan dengan tujuan untuk mengetahui pengaruh penerapan model pembelajaran mind mapping terhadap hasil belajar IPA pada siswa kelas IV SDN Sawangan 07 Kota Depok di masa pandemi Covid-19. Metode dalam penelitian ini menggunakan quasi eksperimen dengan desain penelitian yaitu pretest-posttest nonequivalent control group design. Jumlah sampel dalam penelitian yaitu 64 siswa terdiri atas siswa kelas IV-A dan kelas IV-B dengan teknik sampling total. Pengujian persyaratan analisis untuk uji normalitas menggunakan uji chi kuadrat dan uji homogenitas menggunakan uji-F (Fisher). Setelah dilakukan perhitungan pengujian persyaratan analisis, data yang diperoleh dari kedua kelas tersebut berdistribusi normal dan homogen. Pengujian hipotesis dalam penelitian ini menggunakan uji-t separated varians diperoleh $t_{\text {hitung }}>t_{\text {tabel }}, 2,854>2,000$ maka $\mathrm{H}_{1}$ diterima, artinya terdapat pengaruh dalam penerapan model pembelajaran mind mapping terhadap hasil belajar IPA materi gaya pada siswa kelas IV SDN Sawangan 07 Kota Depok di masa pandemi Covid-19.
\end{abstract}

Kata Kunci: Hasil Belajar, IPA, Model Pembelajaran Mind Mapping.

\section{Abstract}

The background of this research is the low science learning outcomes seen from the minimum completeness criteria namely 68, 43,75\% of fourth class students have grades below minimum completeness criteria. This research was conducted with the aims of knowing whether the application of the mind mapping learning model to science learning outcomes during the Covid-19 pandemic in class IV at SDN Sawangan 07 in Depok City. The method in this research uses a quasi-experimental research design with a pretest-posttest nonequivalent control group design. The number of samples in this research was 64 students consists of students in class IV-A and students in class $I V-B$ with the sampling total. The analysis requirements test namely the normality test using the chi square test formula and homogeneity test using the fisher test formula. After the calculation analysis requirements test, the data obtained from both classes is normally distributed and homogeneous. The hypothesis test uses a $t$-test separated varians obtained $t_{\text {count }}>t_{\text {table }}, 2,854>2,000$ thus $H_{1}$ was accepted, meaning that there is an effect of the mind mapping learning model on science learning outcomes subject matter of force during the Covid-19 pandemic of class IV at SDN Sawangan 07 in Depok City.

Keywords:Learning Outcomes, Science, Mind Mapping Learning Model.

Copyright (c) 2021 Inisti Adelia Ruhama, Erwin

$\checkmark$ Corresponding author :

Email : inistifattah99@gmail.com

DOI $\quad$ : https://doi.org/10.31004/basicedu.v5i5.1422

ISSN 2580-3735 (Media Cetak)

ISSN 2580-1147 (Media Online)

Jurnal Basicedu Vol 5 No 5 Tahun 2021

p-ISSN 2580-3735 e-ISSN 2580-1147 
3842 Pengaruh Penerapan Model Pembelajaran Mind Mapping terhadap Hasil Belajar IPA Siswa Sekolah Dasar di Masa Pandemi Covid-19 - Inisti Adelia Ruhama, Erwin

DOI: https://doi.org/10.31004/basicedu.v5i5.1422

\section{PENDAHULUAN}

Munculnya pandemi Covid-19 secara tiba-tiba, tidak dapat dipungkiri bahwa pendidikan di Indonesia perlu fleksibel untuk membantu situasi pendidikan di sekolah dasar dalam keadaan darurat ini (Djannah et al., 2021). Pandemi Covid-19 menyebabkan perubahan besar pada bidang pendidikan dimana sekolah tidak dilakukan secara tatap muka namun dilakukan dengan pembelajaran jarak jauh atau daring. Berdasarkan Surat Edaran Nomor 4 Tahun 2020 yang didalamnya berisi Pelaksanaan Kebijakan Pendidikan Dalam Masa Darurat Penyebaran Corona (Covid-19), surat edaran tersebut menyatakan bahwa proses pembelajaran memberikan pengalaman belajar yang baru dan bermakna untuk siswa melalui pembelajaran jarak jauh atau daring. Pembelajaran jarak jauh atau daring dilaksanakan dengan tujuan agar memenuhi standar pendidikan dengan pemanfaatan teknologi, dengan pemanfaatan teknologi tersebut diharapkan proses pembelajaran tetap dilaksanakan dengan baik dan efektif selama pandemi Covid-19. Isman dalam Zain, dkk. menyatakan pembelajaran daring adalah pembelajaran yang memanfaatkan jaringan internet untuk proses pembelajarannya (Zain et al., 2021). Pembelajaran daring memerlukan memerlukan internet dan web berbasis teknologi sebagai fasilitas dan sarana pembelajaran untuk membangun pengetahuan dengan mempertimbangkan aspek-aspek pembelajaran (Rasyidiana, 2021).

Belajar dan pembelajaran adalah dua hal yang saling terkait dalam kegiatan edukatif, juga dapat dikatakan sebagai bentuk interaksi antara siswa dengan guru. Belajar dalam arti yang luas dapat dikatakan sebagai suatu proses yang memungkinkan terjadinya perubahan tingkah laku individu sebagai hasil dari terbentuknya respon utama (Hanafy, 2014). Belajar juga dimaknai sebagai proses perubahan perilaku dari hasil interaksi individu dengan lingkungannya, perubahan ini bersifat positif, continiu, terarah, aktif, dan fungsional (Pane \& Darwis Dasopang, 2017). Susanto dalam Mawarni menyatakan bahwa belajar adalah sebuah aktivitas yang dilakukan individu dalam keadaan disengaja serta sadar bertujuan memperoleh pengetahuan dan konsep yang baru sehingga terjadi perubahan perilaku baik dalam berpikir atau bertindak (Mawarni, 2017). Suatu interaksi antara guru dengan siswa serta sumber belajar pada suatu lingkungan belajar disebut dengan pembelajaran (Zulfia Latifah et al., 2020). Proses pembelajaran menurut Pane dan Darwis, didefinisikan sebagai suatu sistem yang melibatkan beberapa komponen yang berinteraksi serta berkaitan agar mencapai suatu hasil yang diharapkan secara optimal dan maksimal sesuai dengan tujuan yang telah ditetapkan (Pane \& Darwis Dasopang, 2017).

Susanto dalam Mawarni mengatakan hasil belajar merupakan perubahan-perubahan yang terjadi dalam diri siswa yang mencakup aspek kognitif, afektif, dan psikomotorik sebagai bagian hasil dari kegiatan belajar yang berlangsung di kelas (Mawarni, 2017). Hasil belajar merupakan pola perbuatan, pengertian, nilai-nilai, sikap/perilaku, apresiasi, dan keterampilan (Septia, 2017). Sukmadinata dalam Iswanto mengatakan bahwa hasil belajar (achievement) di sekolah bertujuan menggambarkan seberapa besar penguasaan siswa terhadap materi pelajaran yang dipelajarinya, tingkat penguasaan tersebut dapat dinyatakan dalam bentuk angka maupun huruf (Iswanto, 2017). Menurut Slameto dalam Raharjo menyatakan bahwa hasil belajar merupakan sebuah proses usaha seseorang agar memperoleh perubahan tingkah laku yang baru sebagai bagian dari hasil pengalaman interaksi seseorang dengan lingkungan (Raharjo \& Kristin, 2019).

Pada dasarnya, ilmu pengetahuan alam bertujuan untuk mempersiapkan siswa agar siap menghadapi situasi di sekitar mereka karena dengan belajar IPA siswa dapat belajar untuk memahami fenomena alam yang terjadi disekitar mereka (Zulfadewina et al., 2020). Ilmu Pengetahuan Alam berkembang dari fenomena, melakukan eksperimen, pengambilan data untuk dianalisis serta menghasilkan solusi dalam masalah kehidupan, dalam faktanya masih ada pembelajaran yang berpusat pada guru (Zulherman et al., 2020). Ahmadi dalam Cahyani menyatakan bahwa IPA adalah suatu ilmu yang mempelajari alam semesta dan segala isinya. Sedangkan menurut Susanto, IPA merupakan salah satu dari mata pelajaran wajib atau pokok dalam kurikulum pendidikan yang diterapkan di Indonesia pada jenjang sekolah dasar (Cahyani, 2019). IPA juga 
3843 Pengaruh Penerapan Model Pembelajaran Mind Mapping terhadap Hasil Belajar IPA Siswa Sekolah Dasar di Masa Pandemi Covid-19 - Inisti Adelia Ruhama, Erwin

DOI: https://doi.org/10.31004/basicedu.v5i5.1422

dapat didefinisikan sebagai disiplin ilmu yang mempelajari berbagai keadaan dan kejadian alam untuk mengetahui konsep, fakta, sikap ilmiah, dan proses penemuan secara sistematis melalui percobaan (Kumala, 2019).

Berdasarkan observasi yang telah dilakukan pada siswa kelas IV di SD Negeri Sawangan 07 tahun pelajaran 2020/2021, Kriteria Ketuntasan Minimal (KKM) muatan pembelajaran IPA pada semester 1 terbilang rendah yaitu 68. Selain itu didukung oleh data sekunder berupa hasil belajar IPA pada penilaian tengah semester ganjil dimana 14 siswa dari 32 siswa $(43,75 \%)$ siswa memiliki nilai dibawah KKM. Hal ini dapat disebabkan karena pembelajaran yang dilakukan selama pandemi kurang melatih keterampilan proses dan sikap ilmiah siswa yang hanya melakukan pembelajaran sebatas melihat video dan mengerjakan soal IPA sehingga siswa kurang menangkap materi tersebut. Seorang guru harus mengajar dengan kreatif dalam menyampaikan materi pelajaran, agar proses pembelajaran di kelas berlangsung dengan menyenangkan dan efektif. Salah satu model pembelajaran yang dapat diterapkan yaitu mind mapping, selain menyenangkan juga dapat membantu siswa meningkatkan kreativitas dan hasil belajar.

Tony Burzan dalam Iswanto mengatakan bahwa mind mapping merupakan suatu cara menempatkan informasi kedalam otak dan mengambilnya kembali ke luar otak, melalui kegiatan mencatat yang kreatif dan efektif yang secara harfiah yaitu memetakan pikiran (Iswanto, 2017). Azizah dalam Setyowati, mengemukakan bahwa mind mapping merupakan cara yang efektif dan efisien dimana data dimasukan, disimpan dan dikeluarkan dari otak. Mind mapping adalah grafik konkret ilustrasi yang mengidentifikasikan konsep tunggal terkait dengan konsep lainnya dalam kategori sama. Anip berpendapat bahwa mind mapping adalah instrument untuk membantu memahami masalah dan membuat rencana untuk semua informasi yang dikumpulkan. Madyono menyatakan bahwa pemetaan konsep merupakan salah satu cara mengembangkan aktivitas berpikir ke segala arah dan menangkap berbagai pemikiran dari berbagai sudut (Setyowati et al., 2019). Swadarma dalam Mawarni berpendapat bahwa mind mapping yaitu cara mencatat yang menarik, efektif, efisien, kreatif, berdaya guna serta mudah bertujuan mengembangkan pemikiran dan ide sesuai dengan mekanisme kerja otak, dapat dikatakan sebagai suatu metode untuk menuangkan gagasan yang terdapat didalam pikiran (Mawarni, 2017). Model pembelajaran mind mapping adalah model peta konsep dimana sebagai alat untuk menyampaikan materi pembelajaran yang bertujuan mendorong siswa berpikir kritis dengan memecahkan permasalahan, siswa juga diarahkan untuk mengidentifikasi permasalah, mencari pemecahan masalah dan menemukan cara pemecahan masalah yang efektif selanjutnya melakukan tindak lanjut(Marxy, 2017). Implementasi mind mapping secara langsung dapat dilihat dengan meminta siswa membuat mind mapping agar menyelesaikan permasalahan yang dikaji ataupun dengan menampilkan mind mapping buatan guru.

Dalam penelitian terdahulu oleh (Susanti, 2016) hasil belajar siswa meningkat setelah menerapkan metode mind mapping pada proses pembelajaran. Selain itu dalam penelitian lainnya (Nazliah et al., 2019) disimpulkan bahwa dibandingkan dengan penerapan model pembelajaran konvensional model dikelas, pembelajaran mind mapping lebih berpengaruh serta efektif untuk meningkatkan hasil belajar. Model pembelajaran mind mapping menunjukan hasil yang positif terhadap hasil belajar siswa kelas V SD Gugus Mahesa Jenar dibandingkan dengan model direct instruction (Septia, 2017). Diharapkan dengan digunakannya model pembelajaran mind mapping dikelas IV SD Negeri Sawangan 07 Kota Depok, hasil belajar IPA materi gaya mengalami peningkatan dimana $43,75 \%$ siswa masih memiliki nilai IPA dibawah KKM. Penelitian ini dilakukan dengan tujuan untuk mengetahui apakah terdapat pengaruh yang signifikan dan positif dalam penerapan model pembelajaran mind mapping terhadap hasil belajar IPA materi gaya pada siswa kelas IV sekolah dasar di masa pandemi Covid-19 yang mana pembelajaran dilakukan secara daring melalui berbagai platform digital seperti google meet dan google form. 
3844 Pengaruh Penerapan Model Pembelajaran Mind Mapping terhadap Hasil Belajar IPA Siswa Sekolah Dasar di Masa Pandemi Covid-19 - Inisti Adelia Ruhama, Erwin

DOI: https://doi.org/10.31004/basicedu.v5i5.1422

\section{METODE PENELITIAN}

Pada penelitian ini metode penelitian yang diterapkan yaitu quasi eksperimen dengan desain penelitian pretest-posttest nonequivalent control group design. Metode penelitian quasi eksperimen (eksperimen semu) didefinisikan sebagai penelitian eksperimen melalui uji coba untuk mengontrol atau memanipulasi variabel yang relevan. Pretest-posttest nonequivalent control group design merupakan desain penelitian yang dilakukan dua kelompok/dua kelas yaitu kelas kontrol dan juga kelas eksperimen. Kelas eksperimen diberikan perlakuan dengan menerapkan model pembelajaran mind mapping, sedangkan kelas kontrol diberikan perlakukan dengan model teacher centered learning (TCL).

Tabel 1. Desain Penelitian

\begin{tabular}{llll}
\hline Kelas & Pretest & Treatment & Posttest \\
\hline $\mathrm{E}$ & $\mathrm{O}_{1}$ & $\mathrm{X}_{1}$ & $\mathrm{O}_{2}$ \\
\hline $\mathrm{X}$ & $\mathrm{O}_{3}$ & $\mathrm{X}_{2}$ & $\mathrm{O}_{4}$ \\
\hline
\end{tabular}

Keterangan:

E : Kelas eksperimen dengan model pembelajaran mind mapping/ IV-B

$\mathrm{K}$ : Kelas kontrol dengan model pembelajaran TCL / IV-A

$\mathrm{O}_{1} \quad$ : Hasil belajar kognitif awal kelas eksperimen

$\mathrm{O}_{2}$ : Hasil belajar kognitif akhir kelas eksperimen

$\mathrm{O}_{3}$ : Hasil belajar kognitif awal kelas kontrol

$\mathrm{O}_{4} \quad$ : Hasil belajar kognitif akhir kelas kontrol

Populasi merupakan wilayah generalisasi yang terdiri atas jumlah subjek/objek tertentu yang telah ditetapkan oleh peneliti untuk dipelajari (Sugiyono, 2017). Populasi pada penelitian ini yaitu seluruh siswa kelas IV di SD Negeri Sawangan 07 Kota Depok tahun ajaran 2020/2021. Sampel merupakan bagian dari jumlah dan karakteristik yang dimiliki oleh populasi. Sampel yang diteliti adalah seluruh kelas IV-A berjumlah 32 siswa dan kelas IV-B berjumlah 32 Siswa, sehingga total sampel dalam penelitian yaitu 64 siswa. Teknik pengambilan sampel yang digunakan yaitu sampel jenuh (sampling total) dimana semua anggota populasi dijadikan sebagai sampel.

Teknik pengumpulan data pada penelitian ini menggunakan pretest dan posttest yang dilakukan sebelum dan sesudah pembelajaran untuk mengetahui hasil belajar IPA pada kelas IV. Jenis Instrumen menggunakan tes dalam bentuk pretest dan posttest berupa pilihan ganda sebanyak 25 soal, tes dilakukan menggunakan google form. Pengujian validitas dilakukan dengan rumus korelasi biserial, sedangkan uji reliabilitas menggunakan rumus KR-20 (Kuder Richardson). Teknik analisis data dalam pengujian persyaratan analisis untuk uji normalitas dalam penelitian ini menggunakan uji chi kuadrat, sedangkan untuk uji homogenitas dilakukan dengan uji-F (Fisher). Pada penelitian ini pengujian hipotesis menggunakan uji-t rumus separated varians dengan taraf signifikan 0,05 atau 5\%(Mahendra, 2017).

\section{HASIL DAN PEMBAHASAN}

Perhitungan uji validitas menggunakan rumus korelasi biserial, dimana butir soal dalam instrumen dikatakan valid jika nilai $r_{\text {pbis hitung }}>r_{\text {tabel }}$ sedangkan butir soal dikatakan tidak valid jika nilai $r_{p b i s}$ hitung $<r_{\text {tabel }}$. Setelah dilakukan uji coba instrumen dari 40 soal pilihan ganda yang diuji coba, hasil perhitungan uji validitas diperoleh 25 butir soal valid dan 15 butir soal tidak valid. Selanjutnya 25 butir soal akan digunakan sebagai instrumen penelitian berupa pretest maupun posttest untuk mengukur hasil belajar IPA siswa kelas IV. 
Tabel 2. Hasil Perhitungan Uji Validitas

\begin{tabular}{lll}
\hline Keterangan & Jumlah Soal & Nomor Soal \\
\hline Valid & 25 & $\begin{array}{l}1,2,3,4,5,6,7,9,12,15,17,19,20,22,23,24,25,28, \\
29,32,34,36,38,39,40\end{array}$ \\
\hline Tidak Valid & 15 & $8,10,11,13,14,16,18,21,26,27,30,31,33,35,37$ \\
\hline
\end{tabular}

Butir soal dalam instrumen yang telah dinyatakan valid sejumlah 25, selanjutnya dilakukan uji reliabilitas dengan menggunakan KR-20 (Kuder Richadson). Soal instrumen dikatakan reliabel jika nilai $\mathrm{r}_{\text {hitung }}>\mathrm{r}_{\text {tabel}}$, sedangkan soal instrumen dikatakan tidak valid apabila nilai $\mathrm{r}_{\text {hitung }}<\mathrm{r}_{\text {tabel. }}$. Berikut hasil uji reliabilitas:

Tabel 3. Hasil Perhitungan Uji Reliabilitas

\begin{tabular}{llll}
\hline $\mathbf{k}$ & $\boldsymbol{\alpha}$ & $\mathbf{r}_{\text {hitung }}$ & $\mathbf{r}_{\text {tabel }}$ \\
\hline 25 & 0,05 & 0,886 & 0,325 \\
\hline
\end{tabular}

Hasil perhitungan uji reliabilitas menggunakan KR-20 dengan taraf signifikan $\alpha=0,05$ dan jumlah item dalam instrumen $\mathrm{k}=25$ diperoleh $\mathrm{r}_{\text {hitung }}>\mathrm{r}_{\text {tabel }} \mathrm{l}=0,886>0,325$ maka instrumen dikatakan reliabel dan layak untuk digunakan sebagai instrumen penelitian. Setelah dilakukan penelitian pada siswa kelas IV di SD Negeri Sawangan 07 Kota Depok diperoleh data nilai pretest dan posttest siswa kelas eksperimen maupun kelas kontrol. Dari data tersebut diperoleh mean, median, modus, simpangan baku, dan varians yang terdapat pada tabel berikut:

Tabel 4. Data Hasil Belajar IPA Kelas Eksperimen dan Kelas Kontrol

\begin{tabular}{lllll}
\hline \multirow{2}{*}{ Keterangan } & \multicolumn{2}{l}{ Kelas Eksperimen } & \multicolumn{2}{l}{ Kelas Kontrol } \\
\cline { 2 - 5 } & Pretest & Posttest & Pretest & Posttest \\
\hline Nilai Tertinggi di Kelas & 100 & 100 & 96 & 100 \\
\hline Nilai Terendah di Kelas & 60 & 64 & 48 & 52 \\
\hline Mean & 78 & 84,3 & 72,75 & 77,87 \\
\hline Median & 82,5 & 85,9 & 78,35 & 80,6 \\
\hline Modus & 80,16 & 85,9 & 77,21 & 82,7 \\
\hline Simpangan Baku & 9,58 & 8,37 & 10,36 & 11.08 \\
\hline Varians & 91,870 & 70,129 & 116.064 & 122,822 \\
\hline
\end{tabular}

Berdasarkan data pada tabel, diperoleh selisih mean (rata-rata) kelas eksperimen antara pretest dan posttest sebesar 6,3 sedangkan selisih mean (rata-rata) kelas kontrol antara pretest dan posttest sebesar 5,12 dapat dilihat selisih kelas kontrol lebih rendah dibandingkan dengan mean kelas eksperimen. Selain itu selisih antara posttest kelas ekperimen dengan posttest kelas kontrol sebesar 6,43 sehingga dapat disimpulkan bahwa terdapat perbedaan pengaruh yang signifikan pada kelas eksperimen dengan menggunakan model pembelajaran mind mapping mendapatkan nilai hasil belajar IPA yang lebih tinggi dibandingkan dengan kelas kontrol yang menggunakan model pembelajaran TCL pada pembelajaran secara daring di masa pandemi Covid-19.

Uji normalitas diperlukan agar membuktikan bahwa data hasil penelitian yang berupa nilai hasil belajar kognitif awal (pretest) maupun hasil belajar kognitif akhir (posttest) pada kelas eksperimen dan kelas kontrol 
berdistribusi normal. Pada penelitian ini menggunakan uji chi kuadrat untuk uji normalitas. Setelah nilai chikuadrat diperoleh, maka nilai tersebut dibandingkan dengan tabel chi-kuadrat dimana taraf signifikan $\alpha=0,05$ dan $\mathrm{dk}=\mathrm{k}-1$. Jika $\mathrm{X}_{\text {hitung }}<\mathrm{X}_{\text {tabel }}^{2}$ maka dapat disimpulkan bahwa sebaran data untuk penelitian dari populasi yang berdistribusi normal. Berikut hasil yang diperoleh dari perhitungan uji normalitas:

Tabel 5. Hasil Uji Normalitas Kelas Eksperimen dan Kelas Kontrol

\begin{tabular}{|c|c|c|c|c|}
\hline Hasil Belajar & Kelas & $\mathbf{n}$ & $\mathbf{X}^{2}$ hitung & $\mathbf{X}_{\text {tabel }}^{2}$ \\
\hline \multirow{2}{*}{ Pretest } & Eksperimen (IV-B) & 32 & 8,863 & \multirow{4}{*}{11,07} \\
\hline & Kontrol (IV-A) & 32 & 9,795 & \\
\hline \multirow{2}{*}{ Posttest } & Eksperimen (IV-B) & 32 & 9,159 & \\
\hline & Kontrol (IV-A) & 32 & 7,409 & \\
\hline
\end{tabular}

Pada tabel diatas dapat disimpulkan bahwa data hasil belajar pretest-posttest pada kedua kelas memiliki nilai $\mathrm{X}_{\text {hitung }}^{2} \mathrm{X}_{\text {tabel }}^{2}$ maka artinya data dari kedua kelas tersebut dapat dikatakan berdistribusi normal. Selain diperlukan uji normalitas dalam persyaratan analisis juga dilakukan uji homogenitas untuk mengetahui apakah data penelitian pada kedua kelas homogen atau tidak homogen. Berikut hasil perhitungan uji homogenitas menggunakan uji-F (Fisher) dengan dk pembilang dan dk penyebut $=31$ dan taraf signifikan $\alpha=0,05$ atau $5 \%$ :

Tabel 6. Hasil Uji Homogenitas Kelas Eksperimen dan Kelas Kontrol

\begin{tabular}{llllll}
\hline $\begin{array}{l}\text { Hasil } \\
\text { Homogenitas }\end{array}$ & Kelas & $\mathbf{n}$ & Varians & F $_{\text {hitung }}$ & F $_{\text {tabel }}$ \\
\hline \multirow{2}{*}{ Pretest } & Eksperimen (IV-B) & 32 & 91,870 & \multirow{2}{*}{1,263} & \\
\cline { 2 - 4 } & Kontrol (IV-A) & 32 & 116,064 & \\
\cline { 1 - 4 } Posttest & Eksperimen (IV-B) & 32 & 70,129 & \multirow{2}{*}{1,751} \\
\cline { 2 - 4 } & Kontrol (IV-A) & 32 & 122,822 & \\
\hline
\end{tabular}

Berdasarkan tabel diatas disimpulkan bahwa perhitungan uji homogenitas kedua kelas $\mathrm{F}_{\text {hitung }}<\mathrm{Ft}_{\text {abel }}$ artinya data kedua kelas tersebut dapat dikatakan homogen. Setelah melakukan pengujian persyaratan analisis yaitu uji normalitas dan homogenitas antara kelas eksperimen menggunakan model pembelajaran mind mapping dan kelas kontrol menggunakan model pembelajaran TCL dapat diketahui bahwa data dari kedua kelas berdistribusi normal dan homogen baik hasil belajar kognitif awal (pretest) maupun hasil kognitif akhir (posttest). Pada pengujian hipotesis berdasarkan data yang berdistribusi normal dan homogen antara kedua kelas maka dilakukan uji hipotesis dengan uji-t separated varians. Berikut hasil perhitungan uji hipotesis:

Tabel 7. Hasil Uji Hipotesis

\begin{tabular}{lllll}
\hline Kelas & $\mathbf{n}$ & Mean & $\mathbf{t}_{\text {hitung }}$ & $\mathbf{t}_{\text {tabel }}$ \\
\hline Eksperimen (IV-B) & 32 & 84,3 & & \\
\cline { 1 - 3 } Kontrol (IV-A) & 32 & 77,87 & & 2,000 \\
\hline
\end{tabular}

Hasil penghitungan uji-t untuk hasil belajar kognitif akhir (posttest) IPA antara kelas eksperimen dan kelas kontrol diperoleh $\mathrm{t}_{\text {hitung }}=2,854$ dengan taraf signifikansi $\alpha=0,05$ atau $5 \%$ dan $\mathrm{dk}=\left(\mathrm{n}_{1}+\mathrm{n}_{2}\right)-2=$ $(32+32)-2=64$ maka diperoleh ttabel $=2,000$. Berdasarkan hal tersebut dapat disimpulkan bahwa $t_{\text {hitung }}>$ $\mathrm{t}_{\text {tabel }}=2,854>2,000$ maka $\mathrm{H}_{1}$ diterima artinya terdapat pengaruh dalam penerapan model pembelajaran mind 
3847 Pengaruh Penerapan Model Pembelajaran Mind Mapping terhadap Hasil Belajar IPA Siswa Sekolah Dasar di Masa Pandemi Covid-19 - Inisti Adelia Ruhama, Erwin

DOI: https://doi.org/10.31004/basicedu.v5i5.1422

mapping di masa pandemi Covid-19 terhadap hasil belajar IPA materi gaya pada siswa kelas IV SD Negeri Sawangan 07 Kota Depok. Berdasarkan pengujian hipotesis menggunakan uji-t diperoleh hasil yang tertera pada tabel diatas serta melihat dari mean atau rata-rata hasil belajar kognitif akhir (posttest) kelas eksperimen $(84,3)$ lebih besar dari rata-rata hasil belajar kognitif akhir (posttest) kelas kontrol $(77,8)$, dapat disimpulkan bahwa model pembelajaran mind mapping yang diterapkan pada kelas eksperimen lebih baik dan efektif dibandingkan dengan model pembelajaran TCL pada kelas kontrol selama sistem pembelajaran jarak jauh atau daring. Sehingga dapat dikatakan bahwa model pembelajaran mind mapping berpengaruh secara signifikan terhadap hasil belajar IPA materi gaya selama masa pandemi Covid-19 yang menerapkan sistem pembelajaran daring pada siswa kelas VI di SD Negeri Sawangan 07 Kota Depok.

Berdasarkan seluruh hasil perhitungan dapat disimpulkan bahwa pembelajaran yang diterapkan dengan model pembelajaran mind mapping dapat memberikan bantuan pada kegiatan pembelajaran jarak jauh (daring) di masa pandemi Covid-19 dimana siswa dapat menangkap materi yang disampaikan dengan baik serta meningkatkan kreativitas siswa dengan membuat mind mapping sehingga memudahkan siswa dalam belajar dan belajar terasa lebih menyenangkan. Dalam penelitian terdahulu yang dilakukan oleh Luvirta Tiyas Mawarni (Mawarni, 2017) yang dilakukan di SD Negeri Tambah Dadi pada siswa kelas IV, berdasarkan hasil analisis data dan pembahasan penelitian menunjukan bahwa terdapat pengaruh dalam metode mind mapping terhadap hasil belajar matematika pada siswa kelas IV. Pengaruh tersebut bisa dilihat nilai rata-rata hasil belajar kelas eksperimen $(71,8)$ lebih tinggi dibandingkan dengan nilai kelas kontrol $(60,1)$. Hal ini menunjukan bahwa hasil penelitian yang dilakukan oleh peneliti di Kelas IV SD Negeri Sawangan 07 Kota Depok sejalan dengan hasil penelitian yang dilakukan Mawarni dimana metode pembelajaran tersebut dapat meningkatkan hasil belajar siswa, baik dalam mata pelajaran matematika maupun IPA. Selain itu penelitian ini juga linear dengan penelitian yang dilakukan oleh (Zulfia Latifah et al., 2020) yang dilaksanakan di MI Miftahul Falah pada siswa kelas VI dimana metode mind mapping meningkatkan hasil belajar dan kreativitas siswa dalam proses pembelajaran PKn. Pada penelitian tersebut menjelaskan bahwa ketika pembelajaran berlangsung menggunakan metode mind mapping berhasil meningkatkan kreativitas dan hasil belajar pada siswa dibandingkan sebelum menerapkan mind mapping nilai siswa cukup rendah. Hasil data tersebut dapat disimpulkan bahwa penerapan metode mind mapping ini dapat meningkatkan kreativitas dan hasil belajar siswa, dengan demikian metode atau model pembelajaran ini dapat dicobakan dan diteliti lebih lanjut apakah mempunyai kontribusi yang sama untuk bidang ilmu lainnya.

\section{KESIMPULAN}

Simpulan dari penelitian ini yaitu sebelum menggunakan model pembelajaran mind mapping 43,75\% siswa memiliki nilai dibawah KKM, namun ketika pembelajaran dilakukan menggunakan model pembelajaran mind mapping hanya 2 dari 32 siswa $(6,25 \%)$ yang masih memiliki nilai dibawah KKM. Hal ini membuktikan bahwa penerapan model pembelajaran mind mapping dapat meningkatkan hasil belajar IPA materi gaya siswa kelas IV pada masa pembelajaran daring di masa pandemi Covid-19, dengan model ini pembelajaran yang sebelumnya tidak menarik menjadi lebih menyenangkan dan menjadikan siswa lebih aktif dikelas sehingga hasil belajar siswa mengalami peningkatan dan mencapai tujuan dari pembelajaran. Berdasarkan hasil perhitungan juga dapat diketahui bahwa penerapan model pembelajaran mind mapping berpengaruh terhadap hasil belajar IPA materi gaya pada siswa kelas IV di SD Negeri Sawangan 07 Kota Depok, walaupun tidak diterapkan secara luring (tatap muka) model pembelajaran ini juga dapat diterapkan pada sistem pembelajaran daring/ pembelajaran jarak jauh karena adanya pandemi Covid-19. 
3848 Pengaruh Penerapan Model Pembelajaran Mind Mapping terhadap Hasil Belajar IPA Siswa Sekolah Dasar di Masa Pandemi Covid-19 - Inisti Adelia Ruhama, Erwin

DOI: https://doi.org/10.31004/basicedu.v5i5.1422

\section{DAFTAR PUSTAKA}

Cahyani, A. W. (2019). Peningkatan Hasil Belajar Melalui Media Pembelajaran Ipa Berbasis Metode Montessori Di Kelas Iv Sd Negeri Puren Tahun Ajaran 2018/2019. 87(1,2), 149-200.

Djannah, M., Zulherman, \& Nurafni. (2021). Kahoot Application For Elementary School Students: Implementations Of Learning Process From Distance During Pandemic Period Of Covid 19. Journal Of Physics: Conference Series, 1783(1), 0-7. Https://Doi.Org/10.1088/1742-6596/1783/1/012121

Hanafy, M. S. (2014). Konsep Belajar Dan Pembelajaran. Lentera Pendidikan: Jurnal Ilmu Tarbiyah Dan Keguruan, 17(1), 66-79. Https://Doi.Org/10.24252/Lp.2014v17n1a5

Iswanto, P. R. (2017). Mind Map Learning Model To Improve The Activities And The Learning Outcomes In The Competency Of Electrical System And Instrument Of Xi Grade Student Of The Motorcycle Engineering Program In Smk Diponegoro Depok Sleman. 5(1), 92-105.

Kumala, N. (2019). Upaya Meningkatkan Hasil Belajar Siswa Dengan Menggunakan Model Pembelejaran Problem Based Intsruction Terhadap Mata Pelajaran Ipa Materi Bumi Dan Alam Semesta Kelas V Min 12 Medan Tahun Pelajaran 2018/2019. 53(9), 1689-1699.

Mahendra, H. H. (2017). Pengembangan Bahan Ajar Flash Book Sejarah Peradaban Indonesia Untuk Meningkatkan Hasil Belajar Siswa Kelas V Sd. Jurnal Pedagogik, 1(2), 31-42. Https://Jurnal.Uns.Ac.Id/Jdc

Marxy, A. (2017). Pengaruh Model Pembelajaran Mind Mapping Terhadap Hasil Belajar Matematika Siswa. Seminar Nasional: Jambore Konseling 3, 00(00), Xx-Xx. Https://Doi.Org/10.1007/Xxxxxx-Xx-0000-00

Mawarni, L. T. (2017). Pengaruh Metode Mind Mapping Terhadap Hasil Belajar Matematika Siswa Kelas Iv Sd Negeri 1 Tambah Dadi.

Nazliah, R., Harahap, R., \& Hasibuan, E. (2019). Jurnal Biolokus Vol: 2 No.2 Juli-Desember 2019. 2.

Pane, A., \& Darwis Dasopang, M. (2017). Belajar Dan Pembelajaran. Fitrah:Jurnal Kajian Ilmu-Ilmu Keislaman, 3(2), 333. Https://Doi.Org/10.24952/Fitrah.V3i2.945

Raharjo, W. T., \& Kristin, F. (2019). Peningkatan Hasil Belajar Ipa Peserta Didik Menggunakan Model Pembelajaran Make A Match Pada Kelas 4 Sd. Satya Widya, 35(2), 168-175. Https://Doi.Org/10.24246/J.Sw.2019.V35.I2.P168-175

Rasyidiana, H. (2021). Problematika Pembelajaran Daring Pada Mata Pelajaran Sains (Ipa) Tingkat Dasar Di Masa Pandemi Covid-19. Jurnal Basicedu, 5(4), 1709-1716.

Septia, T. V. (2017). Pengaruh Model Pembelajaran Mind Mapping Terhadap Hasil Belajar Ips Siswa Kelas $V$ Sd Gugus Mahesa Jenar Kecamatan Ambarawa Kabupaten Semarang Skripsi. 1-146.

Setyowati, D., Samsudi, \& Raharjo, T. J. (2019). The Effectiveness Of Concept Mapping On Social Skills Of $\begin{array}{lllll}\text { Studentsin Social Learning Of Elementary } & \text { School. } & \text { (24), } & 9\end{array}$ Https://Journal.Unnes.Ac.Id/Sju/Index.Php/Jpe/Article/View/28238/12365

Sugiyono. (2017). Statistika Untuk Penelitian. Penerbit Alfabeta.

Susanti, S. (2016). Metode Mind Mapping Untuk Meningkatkan Hasil Belajar Ips Di Sekolah Dasar. Jurnal Pendidikan Guru Sekolah Dasar, 1(1), 25-37. Https://Doi.Org/10.17509/Jpgsd.V1i1.9060

Zain, N. H., Sayekti, I. C., \& Eryani, R. (2021). Problematika Pembelajaran Daring Pada Peserta Didik Di Sekolah Dasar. Jurnal Basicedu, 5(2), 524-532.

Zulfadewina, Sucipto, A., Iba, K., \& Zulherman. (2020). Development Of Adobe Flash Cs6 MultimediaBased Learning Media On Science Subjects Animal Breeding Materials. Jurnal Basicedu, 4(4), 13081314. Https://Doi.Org/10.31004/Basicedu.V4i4.551

Zulfia Latifah, A., Hidayat, H., Mulyani, H., Siti Fatimah, A., \& Sholihat, A. (2020). Penerapan Metode Mind Mapping Untuk Meningkatkan Kreativitas Pada Pembelajaran Pendidikan Kewarganegaraan. Jurnal 
3849 Pengaruh Penerapan Model Pembelajaran Mind Mapping terhadap Hasil Belajar IPA Siswa Sekolah Dasar di Masa Pandemi Covid-19 - Inisti Adelia Ruhama, Erwin DOI: https://doi.org/10.31004/basicedu.v5i5.1422

Pendidikan, 21(1), 38-50. Https://Doi.Org/10.33830/Jp.V21i1.546.2020

Zulherman, Arifudin, R., \& Pratiwi, M. S. (2020). Pengaruh Model Pembelajaran Auditory, Intellectuality, Repetition (Air) Untuk Siswa Sekolah Dasar. Jurnal Basicedu, 4(4), 1267-1266. Https://Doi.Org/10.31004/Basicedu.V4i4.546 